\title{
Editorial
}

\section{La presencia de los metales pesados en los cuerpos de aguas}

La relación de los seres humanos con los metales es muy antigua. La Edad de los Metales, periodo entre 6000 a. C. y 1000 a. C., es muy importante en el despegue evolutivo de la humanidad. El desarrollo de la metalurgia facilitó la fabricación de todo tipo de herramientas, especialmente aquellas empleadas luego en la agricultura, hasta armas con fines no necesariamente defensivos. Nuestra vida sin el uso de los metales - algunas veces no estamos conscientes pues una carcasa polimérica los disimula - sería imposible de imaginar, más en tiempos de pandemia cuando requerimos estar permanentemente interconectados. La lista de productos que ahora disfrutamos contiene artículos que nos son imprescindibles.

Desafortunadamente, este progreso histórico no estuvo desligado de sus consecuencias ambientales. Todas las operaciones propias de la minería y la metalurgia, ejemplos paradigmáticos, así como de cualquier otra actividad industrial, siempre han liberado residuos tóxicos al ambiente. Los problemas básicos han sido no haber previsto sus efectos toxicológicos y ecotoxicológicos, ni haber contado desde el inicio con estrategias apropiadas para minimizar los impactos, garantizar la seguridad ocupacional y buscar alternativas tecnológicas más responsables con el ambiente.

Entre los contaminantes antropogénicos más conocidos están los llamados metales pesados. Aquí cabe hacer dos precisiones: no todo metal pesado es tóxico, y la toxicidad siempre estará relacionada a altas concentraciones en la matriz ambiental de interés. Afortunadamente, la mayoría de países cuenta con normativas ambientales y sistemas de vigilancia, aunque no se puede afirmar su eficacia en todos los casos.

Los metales pesados tóxicos más estudiados son $\mathrm{Hg}, \mathrm{Pb}, \mathrm{As}, \mathrm{Cd}, \mathrm{Cr}, \mathrm{Zn}, \mathrm{Cu}, \mathrm{Ni}, \mathrm{Sn}, \mathrm{Co}$, pero no son los únicos elementos que deben ser monitoreados. Sus efectos en los seres humanos son diversos, según el elemento en cuestión, debido a que son persistentes, se bioacumulan y se magnifican en las cadenas tróficas, y son muy tóxicos aun en bajísimas concentraciones. En algunos casos, los órganos diana son los mismos para varios elementos, exacerbando las condiciones clínicas en caso de una exposición múltiple.

A pesar de los esfuerzos por fiscalizar las actividades industriales y domésticas que están relacionadas con la liberación de metales tóxicos al ambiente, hace décadas que se estudian los cuerpos receptores de este tipo de efluentes. Lagos, lagunas, reservorios, acuíferos subterráneos, aguas marinas y oceánicas, nieve o aguas lluvia inevitablemente acusarán alguna presencia de estos elementos en muestras obtenidas por programas de monitoreo y vigilancia puntuales o sostenidos. Los programas de vigilancia permanente, cuyos resultados son de acceso público usando las tecnologías de información más modernas, son rutinarios y de gran calidad científica en muchos países altamente desarrollados en el control ambiental. Es necesario recordar que un principio ético es que la información medioambiental sea de acceso de todos los ciudadanos de cada país. Recordemos que la educación y la información 
ambiental de calidad son las armas más poderosas que podemos usar para lograr una transición a una sociedad más responsable con nuestro planeta. El planeta que habitamos es nuestra única casa y debemos cuidarla, especialmente de la contaminación en aguas por metales pesados tóxicos.

Dra. Nadia Gamboa

Profesora Principal del Departamento Académico de Ciencias - Sección Química Pontificia Universidad Católica del Perú 